\title{
Del auge del arte textil a la investigación personal.
}


FROM THE BOOM OF TEXTILE ART TO PERSONAL RESEARCH.

\section{ABSTRACT}

This article consists essentially of two parts: the first part is a brief review of the role of women in society and in the textile art. In that, it is analyzed how the textile activity had a great influence in the incorporation of the woman in the labor world and how this phenomenon occurs in parallel to her incorporation into the world of art and the valuation of textile art. We will review some examples of artists who have used or use the textile language to express themselves in the artistic field as an affirmation of their feminine identity.

In the second part, I will expose the main aspects of my own research in the field of textile art though the technique, I call "Sewn collage" the works made with this technique have the characteristic of the collage since they assemble different elements but also join them by stitch, the proper lines of the drawing are reproducer. The characteristic of the painting or traditional drawing are combined with the contemporary art and the expression of the woman from the perspective of the gender.

\section{Keywords}

textile; woman; art; sewn collage; society. 


\section{DEL AUGE DEL ARTE TEXTIL A LA INVESTIGACIÓN PERSONAL.}

\section{RESUMEN}

Este artículo consta esencialmente de dos partes. La primera constituye una breve revisión del papel de la mujer en la sociedad y en el arte a través del arte textil. En ella se analiza cómo la actividad textil tuvo gran influencia en la incorporación de la mujer en el mundo laboral y cómo el fenómeno de la incorporación de la mujer al mundo laboral se produce de modo paralelo a su incorporación al mundo del arte y a la valoración del arte textil. Revisaremos algunos ejemplos de las artistas que han empleado o emplean el lenguaje textil para expresarse en el terreno artístico como afirmación de su identidad femenina.

En segundo lugar, expondré los principales aspectos de mi propia investigación en el campo del arte textil, por medio de la técnica que denomino "Collage cosido". Las obras realizadas con esta técnica tienen las características propias del collage ya que ensamblan distintos elementos, pero además se unen cosiéndolos. De este modo, puntada a puntada, se reproducen las líneas propias del dibujo. Así se aúnan las características de la pintura o dibujo tradicional con el arte contemporáneo y la expresión de la mujer desde la perspectiva de género.

\section{Palabras Clave}

textil; mujer; arte; collage cosido; sociedad. 


\section{INTRODUCCIÓN}

La evolución del concepto de "arte textil" conlleva inevitablemente la revisión del papel de la mujer en la sociedad y en el arte. Pocos tipos de arte o soportes ejemplifican de modo tan claro cómo la mujer pasa del ámbito del hogar y de la anulación del valor de su trabajo a algunos de los lugares más destacados dentro de las más importantes ferias de arte contemporáneo actuales.

Nos encontramos ante un fenómeno social y artístico que merece la pena ser analizado. En esta investigación realizaremos una breve revisión sobre el papel de la mujer en el arte textil y mostraremos cómo la evolución de este se produce de un modo paralelo a la del papel que la mujer juega en la sociedad y, por ende, como individuo creativo en el mundo del arte.

Además, como artista realizaré una breve exposición de mis experimentaciones con los collages cosidos, una técnica hibrida entre el arte textil contemporáneo y artes plásticas tradicionales como la pintura y el dibujo, haciendo hincapié en las muchas posibilidades tanto conceptuales como plásticas que los elementos y materiales del mundo textil contienen para enriquecer el universo creativo del artista.

\section{MEMORIA Y EVOLUCIÓN DEL ARTE TEXTIL}

La actividad textil ha acompañado el progreso del ser humano desde que éste aprendió a usar herramientas; ya en el Paleolítico se han encontrado agujas de hueso, aunque no se conservan tejidos. Desde entonces la actividad textil ha ido evolucionando del mismo modo que lo ha ido haciendo la sociedad. En principio, este tipo de actividad tenía un fin únicamente práctico, pero con el tiempo se fueron añadiendo adornos a las ropas, mantas, o telas en general. En su origen ocupó el mismo lugar que otros elementos del ajuar o la artesanía; esto propició que en su mayoría fuesen confeccionados por mujeres.

\subsection{INICIOS DE UN MEDIO DE EXPRESIÓN FEMENINO}

Durante siglos la expresión plástica ha sido un terreno de expresión masculino; la mujer tenía como cometido la crianza de los hijos y como campo de acción el hogar. En la cultura china, que es la cultura más antigua con continuidad en la actualidad, nos encontramos con una organización social patriarcal.

Algunos opinan que, de las tres doctrinas fundamentales de China (taoísmo, confucianismo y budismo), el taoísmo es la más favorable a la mujer. Hay que reconocer que, en la sociedad china confuciana, el nacimiento de un niño es una fiesta mientras que el de una niña se ve rodeado de discreción. (Despeux, 2003, p. XVII).

En este contexto, el uso de la seda se emplea desde los siglos XVII al XI a.C. durante la dinastía Shang. Aunque no podemos precisar las fechas exactas, se tienen indicios de que las mujeres inventaron un lenguaje milenario, el Nu Shu, que quiere decir "escritura de mujer". "El Nu Shu era dibujado entre las líneas verticales de la escritura china tradicional o cosido en pañuelos, 
abanicos y servilletas enviados como simples regalos" (Metz y Tobin, 1996, p.12). Este lenguaje se desarrolló de este modo ya que en la antigua China no se permitía a las mujeres leer en público, y solo algunas mujeres de familias cultas sabían leer. La escritura Nu Shu era bordada en colchas donde a menudo se contaban historias de mujeres.

Este no es un caso aislado. El impulso creativo es una capacidad inherente a los seres humanos y, como tales, miles de mujeres, durante siglos, encontraron su único medio de expresión en las artes menores o en el campo de lo textil: bordar, coser, tejer o realizar encajes de bolillos era su único campo de expresión plástica.

\subsection{EL SIGLO XX, UN SIGLO DE GRANDES CAMBIOS SOCIALES Y ARTÍSTICOS}

Con la revolución industrial, la mujer comienza a incorporarse al mundo laboral. Desde finales del siglo XIX a comienzos del XX miles de mujeres son empleadas en fábricas textiles tanto en Europa como en Estados Unidos. Es muy conocido el dramático suceso del 25 de marzo de 1911 donde murieron 140 mujeres en la fábrica de camisetas de Triangle Shirtwaist de New York a causa de un incendio. Estas mujeres trabajaban en condiciones insalubres y de explotación laboral; a partir de entonces se creó el Sindicato Internacional de Mujeres Trabajadoras textiles.

A partir de la I Guerra Mundial los cambios se produjeron cada vez con mayor celeridad; la mujer se incorpora de forma más numerosa al mundo laboral y en buena parte lo hace a través del sector textil. En los años veinte diseñadoras como Coco Chanel comienzan a incorporar prendas masculinas al vestuario femenino como, por ejemplo, los pantalones (Madsen, 1998).

El arte es un reflejo de la sociedad y estos cambios sociales afectaron también al mundo del arte y de la educación, ya que cada vez más mujeres tenían acceso a estudios artísticos, aunque este no fue un camino fácil y todavía quedaban muchos prejuicios que superar.

Como uno de los ejemplos más conocidos de reconocimiento del arte textil y de los comienzos de la participación de la mujer en el mundo artístico, podemos citar a la Bauhaus (19191933). Su fundador y primer director, Walter Gropius, propone, junto al Consejo de maestros, un programa pedagógico en el que se eliminan las fronteras entre los géneros artísticos por considerar que la función de todos los géneros es unirse para conseguir "la gran construcción". Con esta idea se pretende unificar el arte y la artesanía con las exigencias propias de la industria (Wick, 1986).

Hay que señalar que, aunque la participación de la mujer en la Bauhaus fue evidente, ya que desde el principio casi la mitad de las matrículas eran de mujeres (Droste, 2019, p.38), no solían ocupar puestos de responsabilidad y eran reconducidas a los talleres de decoración o textil:

Aquí reinaba el modelo de género convencional que veía a las mujeres como "seres naturales" y a los hombres como "seres culturales". Las tareas relacionadas con los niños y el hogar eran femeninas; en el área del arte se les asignaba a lo sumo lo concerniente a los tejidos y la decoración de interiores. (Droste, 2007, p.36)

Pese a considerar natural el asumir una concepción de género tan polarizada, este tipo de políticas se ejercían de un modo soterrado: 
En la Bauhaus de Weimar el Consejo de maestros ejercía una política de selección solapada que favorecía a los candidatos masculinos. Las mujeres fueron asignadas a los talleres de tejidos que eran dirigidos como un "departamento femenino". Solo conseguían plaza en otros talleres a través de un protectorado o superando una fuerte resistencia. (Droste, 2007, p.36)

De este modo, aun en el siglo XX, en una de las instituciones más vanguardistas del momento y en uno de los ambientes más culturalmente avanzados de Europa, la mujer seguía estando relegada a continuar expresándose a través de la producción textil, es decir, de los tapices o la costura.

No obstante, al menos de este modo, los productos textiles serán considerados objetos artísticos y existirá un taller de textil en una escuela de arte donde se impartía formalmente su enseñanza. En esta institución comenzaron su actividad artistas como Anni Albers (Berlin 1899), que fue directora del taller de textil en 1931 y que, además de ser la mujer de Josef Albers, es reconocida por ser una de las pioneras en el arte textil. Cuando la institución fue cerrada por el partido Nazi en 1933, emigró junto a su marido a Estados Unidos donde continuó su labor docente en el Black Mountain College a la vez que su labor artística, convirtiéndose en un referente de modernidad y estilo (Cores, 2017).

Como artista se gestó en las vanguardias europeas conservando el gusto por las formas geométricas y constructivistas. Sin embargo, no dudó en fusionar los estilos indígenas sudamericanos con un concepto más industrial de la sociedad de su época. Tanto sus textos como su obra han sido claves para el reconocimiento del arte textil y el modo de entender el arte contemporáneo. Actualmente Anni Albers está reconocida internacionalmente y su obra se halla en los más importantes museos. Como ejemplo, en Estados Unidos, podemos citar el Metropolitan Museum of Art y el Cooper-Hewitt Museum en New York (Albers, 2001).

No obstante, habrá que esperar a los años sesenta y setenta para que comience a producirse un cambio real y una reivindicación de la mujer como sujeto creativo que dura hasta nuestros días. Es curioso como también en esta época comienza a consolidarse el término "arte textil" tanto en el ámbito artesanal como en el artístico.

Uno de los puntos de inflexión en el arte textil vendrá marcado por la iniciativa de Jean Lurçat, quién en 1962, funda en Lausanne la Primera Bienal Internacional de Tapicería Contemporánea. Los novedosos planteamientos de Lurçat para la renovación del textil y su incorporación a la escena del arte, quedan patentes en dicha muestra al plantear tres directrices: "el tapiz sale del muro", "el tapiz vuelve al muro" y "el tapiz como instalación”. (Colina y Chinchón, 2012, p.184)

Al desubicar al tapiz de su lugar de origen, "el muro", se abren los caminos que serán recorridos hasta la actualidad. Artistas como Sheila Hicks comienzan a crear tapices para después construir esculturas monumentales empleando como materiales la lana y el lino. Shella nace en Estados Unidos para después afincarse en Paris en los años sesenta. En 2018 el Centro Pompidou le dedicó una retrospectiva, y actualmente es reconocida a nivel mundial como una de las más importantes pioneras del arte textil.

Del mismo modo, podemos destacar el papel de Magdalena Abakanowicz, artista polaca que participo en la bienal de Lausanne formando parte de las vanguardias textiles en los años sesenta. 
Realiza grandes tapices y esculturas y durante los setenta construye esculturas con tejidos de sisal y yute, empleando como aglutinante pegamento o resina. Las esculturas representan series de cuerpos humanos o animales, ofreciéndonos un aspecto despersonalizado de la existencia.

Durante esta misma década de los setenta muchas feministas encuentran en el arte textil un medio de expresión; en algunos casos tejiendo y en otros mediante el empleo de la ropa como símbolo social o como referencia al cuerpo y a los roles masculino y femenino. En este sentido, por citar solo un ejemplo, ya que nos es imposible nombrar a todas las artistas que intervinieron en este movimiento, podemos mencionar a Mimi Smith que nace en 1942 y formó parte del movimiento feminista en Estados Unidos en los años sesenta, y se expresa creando prendas femeninas que evidencian los estereotipos que la sociedad impone a la mujer:

Smith usa el textil, ropa en concreto, para hablar de la mujer y las obligaciones que se le han impuesto socialmente, para mostrar que su cuerpo es atacado y utilizado y tiene que protegerse, y para señalar y denunciar el rol asumido por ella. (Larrea, 2007, p.312)

El modo de empleo de la ropa también implica una actitud no solo feminista sino también creativa y de experimentación con nuevos materiales, ya que añade materiales u objetos no habituales; por ejemplo, en un vestido, tetillas de biberón, caramelos plásticos, estropajos u otros objetos del ámbito doméstico femenino.

Numerosas artistas posteriormente se expresarán por medio de la ropa; en este sentido podemos citar los nombres de Jana Sterbak, Beverly Semmes o Susie MacMurray. Se trata pues, de unos años de grandes cambios y reivindicaciones sociales, que repercuten en el mundo del arte. No es de extrañar que, poco a poco, comiencen a sonar cada vez más nombres de artistas femeninas, entre las que debemos destacar a Louise Bourgeois, ya que se expresa en algunas de sus obras mediante el arte textil y es una de las artistas de mayor repercusión.

Louise Bourgeois nace en 1911 en Paris, comenzó con sus primeros dibujos en los años cuarenta, la mayor parte de su obra es escultórica y siempre de un marcado carácter autobiográfico. Aunque el reconocimiento suele ser un camino largo y progresivo, podemos decir que obtuvo su consagración definitiva como artista internacional cuando, en 1982, se realizó una exposición retrospectiva sobre su obra en el Museo de Arte Moderno de Nueva York. Sin embargo, no haremos un recorrido ni por su biografía ni por su extensa obra, que abarca desde las esculturas a las instalaciones, sino que nos centraremos en su trabajo textil. Su primer contacto con este mundo se produjo ya en el seno familiar pues su familia tenía un taller de reparación de tapices antiguos.

Posteriormente, en sus esculturas textiles se expresa mediante trapos cosidos y exhibiendo un aspecto de fabricación casera y en apariencia descuidada. Bourgeois crea una obra inquietante; nos encontramos ante una obra simbolista que materializa las profundidades del inconsciente humano. En su obra Endless pursuit (ver Fig.1), nos presenta una mujer que emerge de una esfera. La totalidad de la escultura está realizada con trapos cosidos haciendo un alarde de la tosquedad del material. Las costuras son evidentes, como si de remiendos se tratara, dándole de este modo a la obra un primitivismo que la dota de una mayor fuerza expresiva. Este tipo de manufactura se repite en sus obras textiles. No olvidemos que sus obras son símbolos que representan la condición femenina. En opinión de Balsega: 


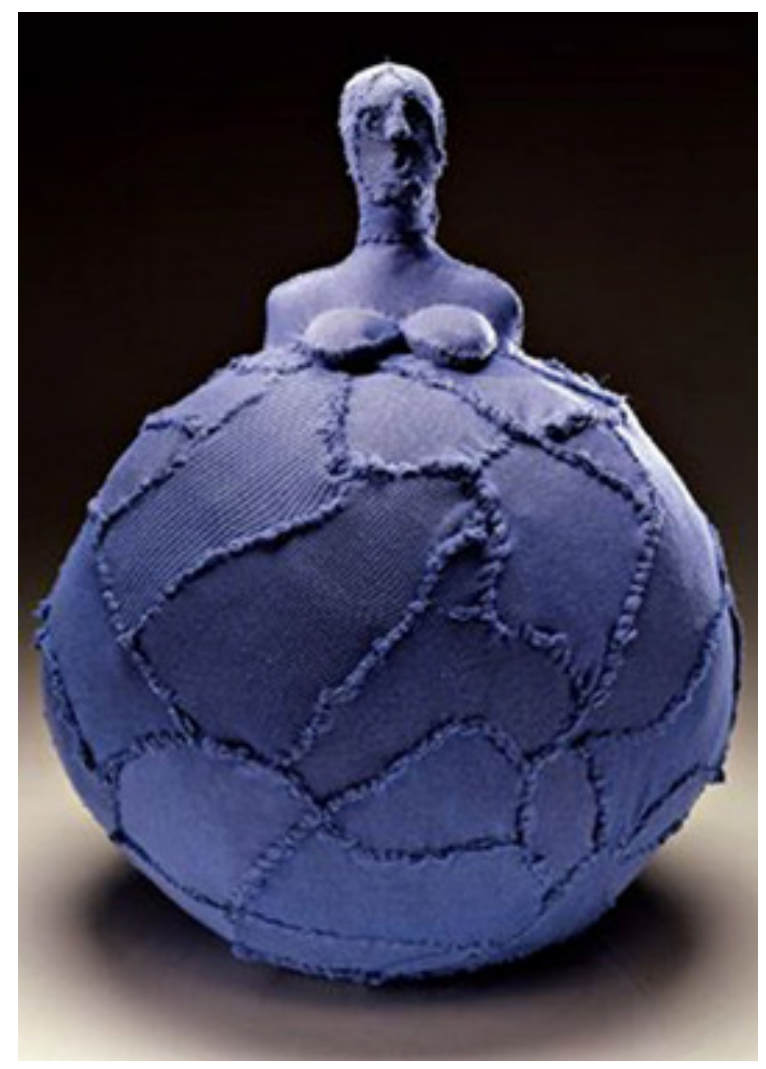

Figura 1. Louise Bourgeois, Endless pursuit, 2000. Fuente: https://www.pinterest.cl/pin/331436853822683903/

(Consultado 20 de octubre 2018)

Bourgeois (...) nos muestra una mujer/vientre que está engendrando al planeta azul, una mujer planetaria que domina el mundo, que es el mundo (las costuras evocan el contorno de los continentes en el planisferio) y que, a pesar de la importancia de lo que está haciendo, iEngendrar el mundo!, la pieza tiene ese aspecto casero, remendado, una pelota de trapo, un tentempié hecho de retales, un juguete sin importancia, al fin y al cabo. (Baselga, 2010, p.312)

De este modo la autora reivindica el gran papel de la mujer como creadora de vida en la sombra. Nos encontramos ante un arte realizado desde la perspectiva de género. Con la incorporación de la mujer al arte se produce un nuevo fenómeno: no solo se incorporan nuevas técnicas y materiales relacionados con el papel tradicional de la mujer, sino también la visión de la propia mujer y de los procesos propiamente femeninos vistos y representados por mujeres.

Podríamos seguir mostrando desde lo individual a la situación general de la mujer, y viceversa, numerosos y diferentes casos, pero en general se reproduce casi siempre el mismo patrón: algunas mujeres artistas deciden incorporar a su arte los conocimientos de costura o de tejidos aprendidos en su educación tradicional, ya sea con mayor o menor intención reivindicativa, 
pero siempre revalorizando artísticamente los saberes y destrezas propias del mundo doméstico y artesanal de las llamadas "artes manuales" (Santoni Rugiu, 1994; Sennett, 2009).

\subsection{EL FENÓMENO DEL ARTE TEXTIL COMO TENDENCIA EN AUGE EN EL ARTE CONTEMPORÁNEO}

Actualmente, aunque la mujer se ha incorporado al mundo artístico, todavía no podemos hablar de una igualdad total. Del mismo modo, tampoco podemos olvidar los legados que durante siglos han estado presentes en la expresión artística de muchas mujeres.

El fenómeno de la incorporación de la mujer al mundo del arte no solo supone la búsqueda de la igualdad, sino que no se quieren olvidar las diferencias. Las mujeres para tener los mismos derechos al reconocimiento artístico no quieren imitar los modos de hacer masculinos. Según Núñez (2000) nos encontramos ante una generación de mujeres que intentan reapropiarse de la noción de diferencia y redefinirla como afirmación.

Este matiz de la actitud femenina en cuanto al modo de entender su propia creación da lugar a un tipo de obras que sin duda enriquecen el arte y aportan una nueva visión, nuevos conceptos y nuevos materiales que hasta entonces nunca habían formado parte del mercado del arte. Esta tendencia se hace sentir en las ferias de arte contemporáneo más importantes. El mundo del textil es una de las muchas innovadoras aportaciones que las mujeres han incorporado al mundo del arte, aunque también en ocasiones, y cada vez más, hay hombres artistas que realizan obras textiles.

Debido a este fenómeno, en la actualidad nos encontramos ante un "boom" del arte textil (Fabian, 2018). El arte textil está presente en las más importantes ferias de arte contemporáneo. En ARCO en Madrid se hace evidente esta tendencia en los últimos años, donde suenan nombres como Carlos Monleon, Elena de Rivero, Asunción Molinos o Joana Vasconcelos, entre otros. Sería imposible nombrar a todos los artistas que actualmente se expresan a través del arte textil. Como ejemplo, en España una de las pioneras en el arte textil fue Teresa de Lanceta y en Latinoamérica destacan nombres como el de Ernesto Neto; ambos exponen actualmente a nivel internacional en las más importantes salas o galerías. Lo mismo ocurre con los encuentros, bienales o exposiciones de arte textil, entre los cuales podemos citar la bienal de arte textil contemporáneo Contextile en Portugal y la VIII Bienal internacional de arte textil (World Textile Art) realizada en Madrid el pasado otoño.

Aun así, hay que señalar que la participación femenina en ARCO ha estado siempre en inferioridad. En 2017 solo el 5\% de las obras expuestas correspondía a artistas españolas; las cifras mejoran lentamente cada año, tanto en ARCO como en otras ferias de arte, pero todavía no podemos hablar de una situación de igualdad (Mayordomo, 2018).

Nos encontramos ante un camino abierto, que merece la pena seguir analizando e impulsando, ya que afecta tanto a la evolución del arte, como a la mejora de la igualdad social. No olvidemos que las salas de arte institucionales, y sobre todo los museos, tienen también una función pedagógica, y que en general, aunque siempre hay excepciones, muestran la misma situación de desigualdad. El arte es un producto de la sociedad y a la vez un escaparate con una evidente repercusión social: el dialogo entre arte y sociedad ha sido continuo a lo largo de la historia (Chadwick, 1992). 


\section{INVESTIGACIÓN PERSONAL DESDE LA PERSPECTIVA DE GÉNERO EN EL ARTE TEXTIL}

La curiosidad versátil debe seguir siendo una característica a destacar en el artista, unida a la necesidad de materializar conceptos, ideas o emociones. Recorrer nuevos caminos es adentrarse en un territorio desconocido que mantiene alerta los sentidos; la hibridación entre los diferentes campos hace brotar la capacidad creativa haciéndola participe de una aventura en la que no hay barreras, salvo las propias del material empleado.

Al fusionar dos campos tan distintos como el textil y la pintura o el dibujo el resultado es un collage realizado a base de puntadas, donde cada elemento pierde su singularidad en favor de un todo que ofrece a la mirada un recorrido visual sugerente.

\subsection{CONSIDERACIONES TÉCNICAS SOBRE EL MÉTODO TEXTIL}

El "collage cosido" se presenta como una técnica llena de posibilidades por sus vinculaciones evidentes con el arte textil, que a su vez está relacionado con las artes visuales, la artesanía, el diseño, el patrimonio cultural y el arte realizado desde la perspectiva de género.

Muchas mujeres artistas hemos recibido una educación profesional en las artes plásticas en universidades o en escuelas de arte, pero a la vez también recibimos una educación tradicional en la que se nos enseñó a coser en la escuela o en el hogar. Este aprendizaje nos capacita para conocer tanto las técnicas pictóricas y de dibujo como las textiles, en el caso de las mujeres que hemos cursado estudios artísticos. Por tanto, no es de extrañar que el auge actual del arte textil y su presencia en la mayor parte de ferias internacionales de arte contemporáneo haya ido en paralelo con el aumento de la presencia femenina en dichos eventos, ya que fuimos las mujeres las que recibimos este tipo de educación.

\subsection{ANTECEDENTES}

La técnica del "Collage cosido" tiene sus orígenes en una indagación plástica que parte de las técnicas tradicionales hasta conectar con los conceptos más recientes del arte contemporáneo.

En un principio, la prioridad era el color. Durante años estudié la pincelada, tanto occidental como oriental: cada elemento plástico ofrece múltiples posibilidades y cada técnica mil modos de expresar sentimientos, conceptos o sensaciones. Desde hace años empleo la técnica del collage, ya que ofrece la posibilidad de crear nuevas texturas.

La indagación comenzó a principios del 2000 con la técnica del óleo sobre collage, uniendo de este modo texturas y color. Esta técnica consistía en pegar, sobre la imprimación ya preparada para el óleo, diversos tipos de papeles, algunos de ellos tintados, coloreados o arrugados previamente.

Después de un largo proceso de investigación y de experimentación con diversos materiales, el hallazgo se produjo de forma natural cuando en vez de papeles empleé telas. Los distintos tejidos proporcionaban la adaptabilidad necesaria para crear volúmenes, además de nuevos 
tipos de texturas y del juego visual que ofrecían los distintos estampados. Para conseguir que la tela quedase con volumen advertí que era mejor coserla que pegarla, y a partir de ahí todo un mundo de posibilidades plásticas empezó a fluir. Como consecuencia de este nuevo proceso, comencé a comprobar que no solo podía coser telas, sino también todo tipo de objetos. Además, todos los conocimientos sobre costura que aprendí durante la infancia y los primeros años de la adolescencia comenzaron a volver a mi mente y redescubrí los distintos tipos de punto, agujas, lanas, hilos y botones; pero dándoles un concepto nuevo, unos valores plásticos y estéticos al margen de una utilidad doméstico-artesanal.

\subsection{INVESTIGACIÓN SOBRE LA TÉCNICA}

Para el artista plástico la experimentación técnica es su campo de investigación, al igual que puede serlo para el científico el laboratorio o para el teórico una biblioteca. La investigación plástica es una investigación empírica y como tal está sujeta al proceso de ensayo y error. Es además una aventura personal, sin subvenciones ni ayudas de ningún tipo, donde todo el riesgo lo asume el artista. Es, por tanto, un camino difícil y poco reconocido, pues nada garantiza los resultados. Solo la intuición de aquello que se quiere conseguir y la necesidad de crear impulsa a seguir adelante.

El proceso de creación en sí constituye, según algunos autores, una fase de la obra más importante que la obra misma. Basándome en este concepto, durante varios años, y paralelamente al empleo de otras técnicas, se gestó una indagación personal en el campo del arte textil hasta llegar a crear la técnica que podemos denominar como "Collage cosido". Aunque también es cierto que algunos collages que llevan óleo podrían considerarse como "técnica mixta", sin embargo, estos collages son fácilmente diferenciables del collage tradicional pegado o de la técnica mixta entendida como un conjunto de técnicas empleadas en una sola superficie.

\subsection{EL “Collage cosido"}

La característica principal del "Collage cosido" es que todos los elementos que lo integran están unidos por hilos o lanas. Es decir, el collage se ensambla cosiéndolo, no pegándolo, lo cual le confiere unas características únicas, ya que el hilo no termina de unir del todo sus elementos; algunos quedan más sueltos que otros creándose así texturas tanto visuales como táctiles.

Este modo de unir los distintos elementos que componen el collage presenta unas dificultades técnicas evidentes: las telas en los cuadros van unidas a los bastidores y a través de estos no se puede coser; por ello, excepcionalmente, en este caso dichos elementos pueden estar pegados o grapados. La parte posterior del cuadro se convierte en una maraña de nudos e hilos que evidencian la dificultad del trabajo realizado (ver Fig.2). 


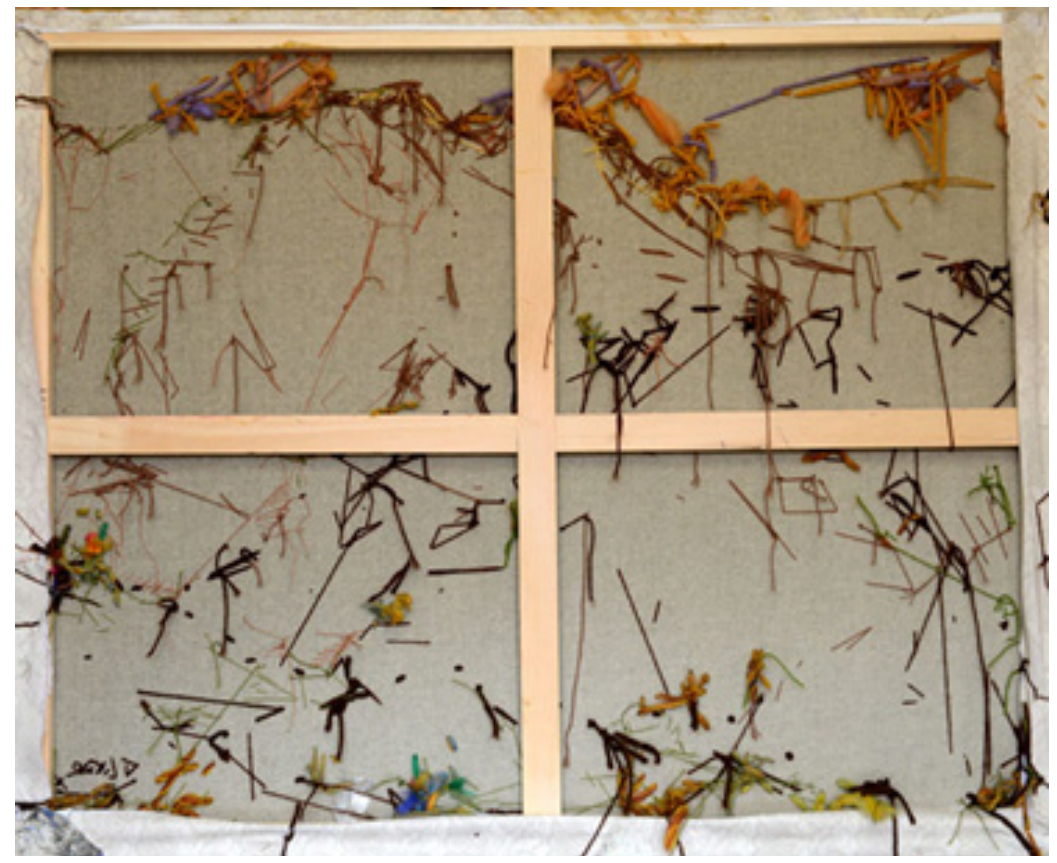

Figura 2. Parte posterior de la obra Matas de esparto sobre tierras áridas. 2015.

\subsection{EL CONCEPTO DEL TIEMPO}

Debido a las dificultades expuestas y a las características propias del trabajo textil, el proceso de creación de estas obras resulta bastante lento, empleándose de uno a varios meses en la realización de cada una de ellas. En este sentido, la obra nos muestra las características propias de un trabajo que es el resultado de un largo proceso de maduración.

El concepto de tiempo cambia por completo; la realización de la obra conlleva una praxis pausada, asumida como un proceso dilatado que no acepta premuras. El tiempo nos da la distancia apropiada para captar las características de cada elemento que luego se pierde en el todo, como las letras en el conjunto de un libro o como los ingredientes de una receta.

El tiempo del proceso se completa con la mirada del espectador, al que se pretende interrogar sin ofrecer una respuesta concreta como resultado. El collage ofrece un recorrido a la mirada en dos sentidos: una mirada de conjunto y una manera distinta de saborear cada elemento. De este modo, tanto el tiempo de creación como el de contemplación de la obra se dilatan, en principio sin una intención previa, sino como resultado del mismo proceso. Un proceso que imprime un carácter específico a la obra como objeto de investigación que nos puede llevar a nuevos hallazgos.

A su vez las telas y las lanas con el paso del tiempo envejecen dándole una mayor solera a la obra. Nada es atemporal, ya que estamos hablando de materia. Este aspecto nos lleva a otro tipo de reflexión que abordaremos en el siguiente punto. 


\section{EL “COLLAGE COSIDO” COMO OBRA MANIPULADORA DE LA MATERIA}

En un mundo cada vez más rodeado de realidad virtual, el collage supone una dosis necesaria de realidad tangible para los sentidos. No podemos nutrirnos solo de las imágenes; el mundo plástico es mucho más diverso y reducirlo a un solo sentido o aspecto supone una pérdida de estímulos para incentivar la creatividad. Cuando se crea es necesario tocar los materiales, oler y mantener un contacto de manipulación real con ellos; de este modo, la implicación del artista en su obra es mayor.

Cuando se realiza un collage, la sola búsqueda de los materiales adecuados ya supone una parte importante del proceso. Es en este punto donde cada material cobra importancia por sí mismo y donde cada proceso de búsqueda del material genera una historia paralela. En ocasiones hay encuentros casuales con los objetos, y otras veces se trata de búsquedas por mercerías, mercadillos o tiendas de telas. También se pueden utilizar partes de ropas viejas o en desuso.

Cualquier pequeño objeto, material, independientemente de la función que se le ha otorgado, encierra en su interior un mundo y puede ser generador de universos. Hasta el material más humilde está cargado de vida. La materia es tangible, es real, ocupa un espacio y un lugar, pero también es transformable y por tanto susceptible de ser manipulada hasta obtener el fin deseado. (Linaza y Sardá, 2018, p.150)

El mestizaje de los soportes artísticos abre un mundo de posibilidades creativas; no solo las telas pueden ser cosidas, también los botones, los plásticos, los papeles, incluso algunos objetos. El hilo no solo une los materiales, sino que representa plásticamente la línea del dibujo. En realidad, se trata de un trabajo de línea, un trazo representado mediante lanas o hilos. En este sentido, son tenidas en consideración todas las variantes plásticas del dibujo: la gestualidad de los trazos o las variaciones de grosor de las líneas, que son cuidadosamente trasladadas al lenguaje textil mediante los distintos tipos de grosor de los hilos o lanas. Es decir, un trazo grueso de dibujo se representa con una lana de mayor grosor y un trazo fino con un hilo fino. Todo, cada paso y cada puntada, está cuidado.

Normalmente la obra parte de un dibujo, apunte o boceto. Debido a la complejidad del lenguaje textil, al menos las líneas generales de la obra se deben tener definidas previamente. Si no se procede de este modo, el riesgo de tener que descoser parcialmente la obra es mayor, y cuando esto se produce no es un proceso fácil; frecuentemente, en estos casos, las puntadas dejan su rastro en la tela, y reconstruirlo todo conlleva más tiempo y esfuerzo. La dirección de las puntadas de la aguja define la línea del dibujo. Debe, por tanto, existir un diálogo constante entre el dibujo y el collage. Este tipo de obras son en sí mismas un proceso de deconstrucción y construcción de espacios plásticos, sujetos a las tensiones arbitrarias y a la vez necesarias que va exigiendo la transformación de la materia en obra autónoma. 


\subsection{LA MATERIALIZACIÓN DEL PROCESO EN LA OBRA PLÁSTICA}

Después de exponer los procesos creativos, podemos mostrar algunos de los resultados de dichos procesos. La obra Nudos (ver Fig. 3) forma parte de una serie de troncos de árboles nudosos y retorcidos que parten de apuntes realizados del natural.

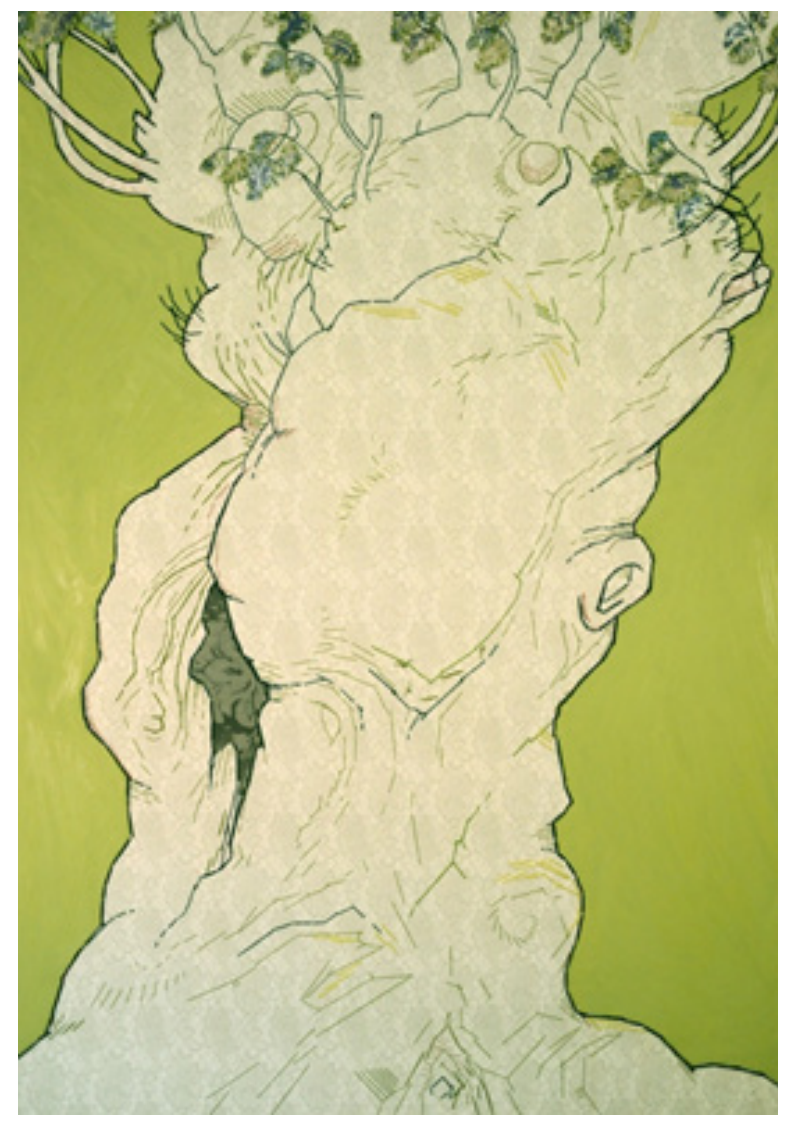

Figura 3. Nudos, 2015. Collage cosido, $162 \times 114 \mathrm{~cm}$.

Esta obra fue seleccionada en el XVI Premio de pintura de la Universidad de Murcia. Aunque personalmente prefiero describir la técnica como "Collage cosido" también podría denominarse "Collage textil" o simplemente "técnica mixta", ya que el fondo está resuelto a base de una capa de óleo sobre lienzo. Se trata pues, de una obra híbrida, donde la corriente contemporánea del arte textil se fusiona con la técnica tradicional del óleo.

Como puede apreciarse en el detalle (ver Fig. 4), el tronco está descrito a base de líneas, al igual que ocurre en el boceto con las líneas de dibujo a lápiz. Por tanto, podemos afirmar que se sigue tratando de un trabajo de línea, solo que esta está confeccionada puntada a puntada. 


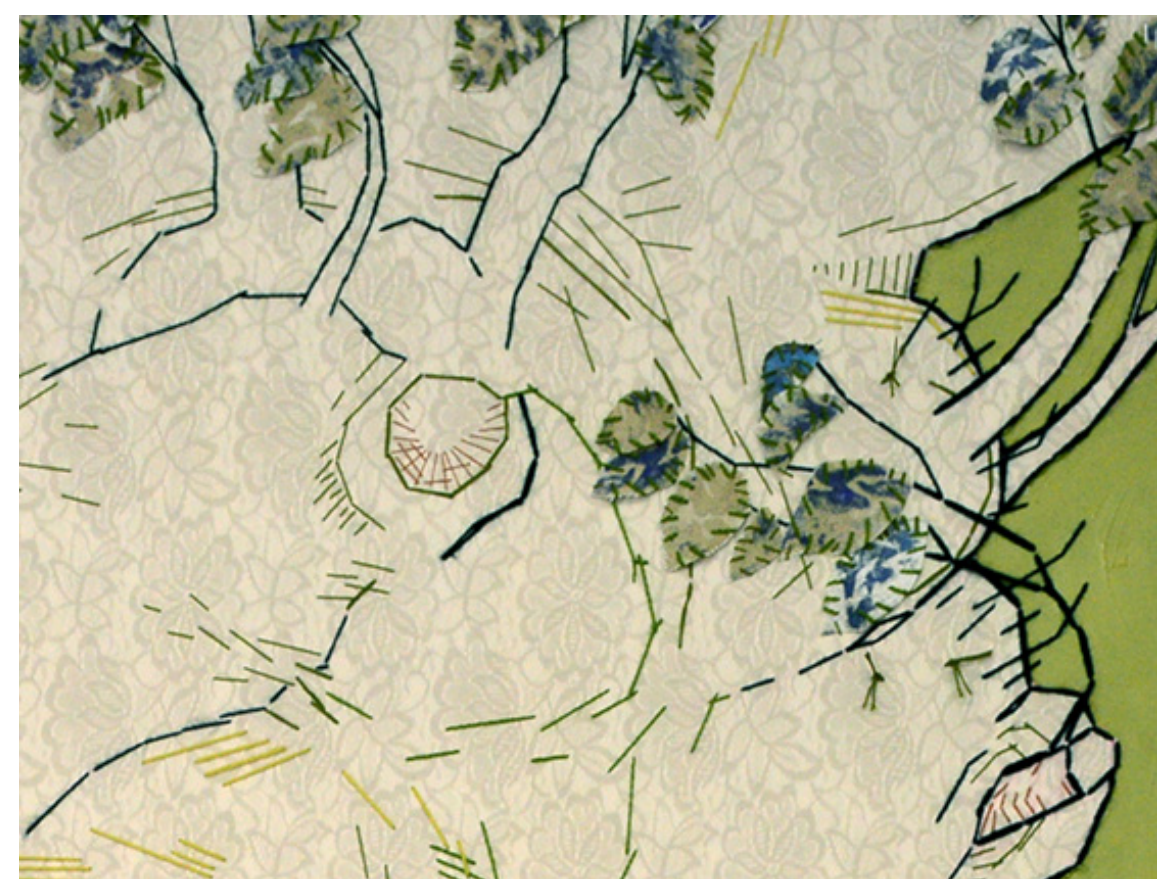

Figura 4. Detalle de la obra Nudos.

Esta transformación de la línea supone el riesgo de perder parte de la frescura y la inmediatez del dibujo. Para que esto no suceda, las líneas son traducidas con la mayor precisión posible; es decir, se cuidan todos los detalles: si en el dibujo hay líneas más finas se traducen al lenguaje textil por hilos o lanas más finos o de un color más suave; al contrario, cuando son líneas más importantes o gruesas, por ejemplo, las que describen el contorno, estas se realizan con una lana más gruesa y de un tono más oscuro. Aun así, es muy difícil conservar la soltura del trazo a mano alzada; sin embargo, el "collage cosido" gana en originalidad y texturas con respecto al dibujo.

Los estampados de las telas contrastan con la textura del óleo produciéndose un juego visual que dinamiza la tensión de la obra. En otras obras se añaden botones u otros objetos del mundo textil. De este modo el collage se ensambla creando un todo unificado. 
Como consecuencia de los argumentos expuestos hasta ahora, podemos afirmar que la corriente del arte textil se encuentra en uno de sus mejores momentos de aceptación en el arte contemporáneo. Este hecho está relacionado con la presencia cada vez mayor de mujeres en las galerías y ferias de arte internacionales. Esto ha sido posible después de un largo proceso tanto de integración social de la mujer en el trabajo como en el mundo del arte. Aunque el arte textil ha sido realizado en muchas ocasiones también por hombres, podemos hablar de una corriente artística que recoge el legado de la educación tradicional de muchas mujeres en el ámbito doméstico-artesanal, convirtiéndose por ende en una seña de identidad femenina y en un arte realizado, en la mayoría de los casos, desde la perspectiva de género.

Como conclusiones de la propia investigación personal, podemos asimismo decir que los "collages cosidos" son el fruto de un largo trabajo de experimentación e investigación en el que se recoge toda la experiencia como pintora y como artista multidisciplinar, al tiempo que se integran los conocimientos sobre las técnicas de costura aprendidas por la mayoría de las mujeres que recibimos una educación tradicional. De este modo, con un ejemplo individual se constata un hecho que afecta a muchas mujeres en la sociedad actual y en particular a mujeres artistas, ya que en la mayoría de los casos hemos recibido unos conocimientos y desarrollado unas destrezas en un terreno concreto, la costura y el textil, vinculado al mundo femenino.

Por tanto, podemos afirmar que los avances sociales y artísticos están muy relacionados, ya que el arte es creado por individuos que participan de unas normas sociales. Del mismo modo, cualquier valoración positiva o negativa de un soporte como obra de arte por parte de la sociedad está relacionada con los valores que tenga dicha sociedad. Es decir, nos encontramos con campos relacionados que interactúan, dando lugar a una evolución conjunta.

En lo referente a la investigación personal también se trata de fusionar diversos campos que en principio pueden parecer no estar relacionados, pudiendo llegar a la conclusión de que la técnica del "Collage cosido" supone la integración de muy diversos aprendizajes ya que aúnan el legado de la educación tradicional de la mujer con la innovación más reciente. Es más, en el aspecto técnico nos encontramos también con otra fusión similar, ya que están presentes, por un lado, las técnicas tradicionales de la pintura y el dibujo y, por otro, tendencias actuales del arte contemporáneo, como la búsqueda de nuevos soportes y materiales, la hibridación o el auge del arte textil.

En síntesis, la fusión entre corrientes diversas enriquece tanto plástica como conceptualmente la investigación artística, incentivando la creatividad y la curiosidad, cualidades muy necesarias para la creación. De este modo, se abre un mundo de posibilidades infinitas que queda abierto a futuras investigaciones. 


\section{Bibliografía}

Albers, A. (2001). Anni Albers: Selected Writtings on Design. Connecticut: Wesleyan University Press.

Baselga, P. (2010). Louise Bourgeois. Simbolismo y fragmentos de la postmodernidad. Anales de la historia del arte, 20, 301-319.

Chadwick, W. (1992). Mujer, arte y sociedad. Barcelona: Editorial Destino.

Colina, L y Chinchón, A. (2012). El empleo del textil en el arte: aproximaciones a una taxonomía. Espacio, Tiempo y Forma, 24, 179-194.

Cores, N. F. (2017). Anni Albers, la mujer que tejió el arte, en el Guggenheim. 20 minutos. Recuperado de https://www.20minutos. es/noticia/3154866/0/anni-albers-tocar-vista-arte-textil-fiber-artmuseo-guggenheim-bilbao/

Despeux, C. (2003). Taoísmo y alquimia femenina. Barcelona: Editorial La Liebre de Marzo.

Droste, M. (2007). Bauhaus 1919-1933. Madrid: Editorial Alianza.

Droste, M. (2019). Bauhaus. Polonia: Editorial Taschen.

Fabian, B. (2018). El boom del arte textil. Elle. Recuperado de https://www.elle.com/es/living/decoracion/g19566106/elboom-del-arte-textil/

Larrea, I. (2007). El significado de la creación de tejidos en la obra de las mujeres artistas. Tesis doctoral. Universidad País Vasco. Facultad de Bellas Artes.

Linaza, M. y Sardá, R. (2018). Jugando con la materia: estrategias para el desarrollo de un lenguaje artístico propio. Arte, individuo y sociedad, 30, 145-158.

Madsen, A. (1998). Coco Chanel. Barcelona: Editorial Circe.

Mayordomo, C. (2018). iEstamos aquí! Las mujeres artistas se hacen visibles en ARCO 2018. Recuperado de: https://tribunafeminista.elplural.com/2018/02/estamos-aqui-las-mujeres-artistasse-hacen-visibles-en-arco-2018/ 
Metz, K. P. y Tobin. L. J. (1996). El Tao de las mujeres. Madrid: Editorial Gaia.

Núñez, M. (2000). El debate igualdad/diferencia en la práctica artística. En M. L. F. Cao. (coord.). Creación artística y mujeres (pp. 165-176). Madrid: Narcea.

Santoni Rugiu, A. (1994). Nostalgia del maestro artesano. México: UNAM.

Sennett, R. (2009). El artesano. Barcelona: Anagrama.

Wick, R. (1986). Pedagogía de la Bauhaus. Madrid: Alianza. 